\title{
EFEITO DE DIFERENTES MATERIAIS DE PELETIZAÇÃO NA DETERIORAÇÃO DE SEMENTES DE TOMATE DURANTE O ARMAZENAMENTO ${ }^{1}$
}

\author{
JOÃO ALMIR OLIVEIRA²; CARLOS EDUARDO PEREIRA3; RENATO MENDES GUIMARÃES ${ }^{4}$; ANTONIO RODRIGUES VIEIRA ${ }^{5}$;
} JOÃO BOSCO CARVALHO DA SILVA 6

\begin{abstract}
RESUMO - O revestimento de sementes de hortaliças é uma técnica bastante utilizada, principalmente para as espécies que possuem sementes pequenas, sendo uma de suas funções, o aumento do tamanho das mesmas para fins de semeadura. Neste contexto, o presente trabalho teve como objetivo revestir sementes de tomate com diferentes materiais, e avaliar seu comportamento durante o armazenamento. Utilizaram como revestimento uma mistura de areia + microcelulose e outra de calcário + microcelulose, contendo ou não o fungicida Rovrin na dosagem de 200g/100 kg de sementes. As sementes revestidas, juntamente com as não revestidas (com ou sem fungicida), foram secadas e embaladas em envelopes de papel comum (embalagem permeável) e em papel laminado (embalagem impermeável) e armazenadas em condições de ambiente no Laboratório de Análise de Sementes da Universidade Federal de Lavras. A avaliação da qualidade das sementes foi realizada a cada quatro meses, por um período de 24 meses, utilizando as seguintes determinações: teste de germinação, envelhecimento acelerado e emergência de plântulas em solo + areia. Pelos resultados obtidos, conclui-se que: sementes revestidas apresentaram germinação mais lenta do que as não revestidas; sementes revestidas com calcário + microcelulose deterioram mais rápido que com areia + microcelulose e sementes tratadas com fungicida em associação com os materiais de revestimento perdem sua qualidade mais rapidamente durante o armazenamento.Verificou-se ainda que sementes revestidas com areia + microcelulose e sem tratamento fungicida mantiveram sua qualidade durante os 24 meses de armazenamento, independente da embalagem utilizada.
\end{abstract}

Termos para indexação: qualidade, germinação, embalagem, fungicida.

\section{EFFECTS OF DIFFERENT PELLETING MATERIALS ON THE DETERIORATION OF TOMATO SEEDS DURING STORAGE}

\begin{abstract}
The pelleting of vegetable seeds is a very common technique, mainly for the species which have small seeds. One of its functions is to increase the seed size for direct sowing. The present study verified the pelleting of tomato seeds with different types of materials and to evaluated the performance during seed storage. The materials used as pelleting coats were sand + microcellulose and limestone + microcellulose, with and without Rovrin fungicide $(200 \mathrm{~g} / 100 \mathrm{~kg}$ of seeds). Raw seeds were covered, and treated with or without fungicides. Then, seeds were dried and put in paper envelopes (permeable) and in aluminum foil (impermeable) and stored at room temperature at the Universidade Federal de Lavras Seed Lab. The evaluation of seed quality was done once every four months, for 24 months, using the following determinations: germination test, accelerated aging and emergence on soil + sand. Covered seeds presented slower germinatnion than the raw seeds. Seeds covered with limestone + microcellulose deteriorated faster than the ones with sand + microcellulose and seeds treated with fungicides in association with the pelletting
\end{abstract}

\footnotetext{
${ }^{1}$ Aceito para publicação em 11/11/2003.

2 Prof. Dr., UFLA; Cx. Postal 37, 37200-000, Lavras, MG; e-mail jalmir@ufla.br

${ }^{3}$ Graduando Agronomia, UFLA; e-mail sementes@ufla.br
}

\footnotetext{
${ }^{4}$ Prof. Dr., UFLA; e-mail renatomg@ufla.br

${ }^{5}$ Dr. Pesquisador, EPAMIG; Cx. Postal 176, 37200-000, Lavras, MG; email arvieira@ufla.br

${ }^{6}$ Dr. Pesquisador, Embrapa; Cx. Postal 218, 70359-970, Brasília, DF; email: jbosco@cnph.embrapa.br
} 
materials lost their quality faster during the storage. Seeds covered with sand + microcellulose and without fungicide maintained their quality for the 24 months of storage, regardless of the packing used.

Index terms: quality, germination, packing, fungicide.

\section{INTRODUÇÃO}

O agricultor tem buscado o máximo aperfeiçoamento dos sistemas de cultivo que lhe possa garantir o êxito técnico e econômico de suas atividades agrícolas, no âmbito de um mercado cada dia mais exigente e competitivo. Dentro deste contexto, as sementes de algumas espécies hortícolas assumem grande importância, em função de apresentarem dificuldades na semeadura direta, devido principalmente à sua forma, tamanho e peso, além da desuniformidade na germinação, infestação por insetos e microrganismos, dormência, entre outras causas.

O recobrimento de sementes constitui uma das técnicas de tratamento no pré-plantio mais promissoras, pelo fato de dar proteção às sementes contra agentes exteriores, possibilitar o fornecimento de nutrientes, oxigênio, reguladores de crescimento, proteção fitossanitária, herbicidas e sobretudo por permitir uma semeadura de precisão em cultivos com plantio direto (Sampaio \& Sampaio, 1994 e Scott, 1989). De qualquer forma, é necessário ter em mente que o principal objetivo do recobrimento da semente é melhorar o comportamento das mesmas, tanto do ponto de vista fisiológico, como econômico.

Tonkin (1979), estudando o efeito do revestimento das sementes sobre o estabelecimento das plântulas de cenoura, cebola, alface e beterraba açucareira, concluiu que, com o uso de sementes recobertas, pode-se conseguir populações ótimas, com altas taxas de emergência e com mínima utilização de mão de obra. Sachs et al. (1981) e Borderon (1989), trabalhando com sementes de fumo, begônia e com sementes compridas e pontiagudas como alface e aipo, demonstraram que o recobrimento atua melhorando a precisão de semeadura. Em relação ao peso das sementes, Scott (1989) afirma que o recobrimento desempenha um importante papel na semeadura aérea, melhorando a projeção balística das mesmas.

A semeadura direta, no caso do pimentão, é apresentada por Rodriguez Del Rinco (1988) como a única técnica de implantação do cultivo que permite obter altas populações de plantas com um custo economicamente razoável. Para reforçar a importância econômica que assume a semeadura direta da cultura do pimentão, trabalho desenvolvido por Garcia \&
Martin Português, citado por Sampaio \& Sampaio (1994), mostra que aproximadamente $45 \%$ da mão de obra empregada no cultivo extensivo do pimentão, se destinam a trabalhos relacionados com a sementeira e o transplante, algo que pode ser minimizado com a semeadura direta. Para o cultivo da beterraba açucareira, Antonov et al. (1978) comprovaram que, apesar de sofrer um pequeno atraso na germinação, o recobrimento das sementes permite alcançar uma semeadura precisa, além de eliminar os custos com transplantes ou desbastes. Marioni (1982), comparando diferentes métodos de semeadura no cultivo de tomate e pimentão, verificou que a semeadura direta foi mais vantajosa economicamente, principalmente quando se utilizam sementes híbridas de alto custo. Também Henrisen (1987), verificou que as sementes de cebola recobertas garantem uma taxa de semeadura e uma distribuição final de plantas ao longo do sulco muito mais uniforme que as sementes desnudas.

Folster et al. (1987), verificaram que a velocidade de emergência e o peso fresco das plântulas provenientes de sementes peletizadas de cenoura e rabanete foram inferiores às sementes nuas. Por outro lado, Coraspe (1993), verificaram que os testes de laboratório não mostraram diferenças significativas na qualidade fisiológica entre sementes peletizadas e nuas de alface, com exceção do teste de envelhecimento artificial e do teste de emergência em campo, nos quais as sementes peletizadas apresentaram melhor desempenho do que as sementes nuas.

Sachs et al. (1981) demonstraram que a germinação de sementes de pimentão foi inibida depois de ter sido realizado o recobrimento. Segundo estes autores, os resultados finais indicaram a possibilidade de que altas concentrações de oxigênio são necessárias para manter um alto nível metabólico na germinação de sementes recobertas, desde o início da embebição até a elongação da radícula. Isto pode ser influenciado fundamentalmente pelo material de recobrimento utilizado, que, de alguma maneira, parece impedir a penetração de oxigênio para a semente. Neste mesmo sentido, Tonkin (1979) revisou muitos trabalhos relativos ao processo de embebição de sementes recobertas, os quais também ressaltaram a importância do tipo de material utilizado no recobrimento, especificando que este não deve desintegrarse durante a embebição, formando uma massa, o que limita- 
ria a passagem de oxigênio e, em alguns casos, da umidade necessária para que ocorra a germinação.

Utilizando diferentes materiais para recobrimento de sementes de tomate e pimentão, Jeong \& Cho (1995), verificaram que a medida em que aumentou a concentração destes materiais, o percentual de germinação das sementes foi reduzido. Também Roos \& Moore (1975) testando o comportamento das sementes de duas cultivares de alface com diferentes tipos de recobrimento, verificaram que sementes recobertas necessitam mais tempo para germinar do que sementes nuas, originando ainda menor peso seco das plântulas. No entanto, após 20 dias, o peso foi recuperado totalmente. Concluíram então que o recobrimento de sementes é a única prática que torna possível a semeadura de precisão de alface sem afetar o desenvolvimento e a produção final. Kitto \& Janick (1985), também testando o efeito do encapsulamento na germinação de sementes de alface, chicória, tomate e cebola, verificaram atraso de um a dois dias no período de emergência de plântulas, porém isto não afetou o estande final e a produção.

Outra prática importante utilizada durante o revestimento é a aplicação de protetores químicos para o tratamento de sementes, visando o controle e/ou proteção contra insetos, microrganismos e roedores (Sampaio \& Sampaio, 1994). Essa técnica tem sido bastante promissora, uma vez que muitos produtos não podem ser usados conjuntamente, ou por motivos de interações incompatíveis de seus princípios ativos ou por serem demasiadamente tóxicos, ocasionando sérios problemas à integridade das sementes. Neste sentido, Rosso et al. (1995) relatam o efeito benéfico do uso de inseticidas e fungicidas junto ao material utilizado no revestimento das sementes de beterraba. Também Laska et al. (1986) trataram sementes de couve com carbofuram, benomyl e thiram, com e sem adição de um material de revestimento, e verificaram que, em condições de campo, o tratamento de sementes revestidas promoveu aumento significativo na produção.

Com relação à conservação de sementes recobertas, Roos \& Moore (1975) relatam que o armazenamento de sementes de alface, recobertas com diferentes materiais, resultou numa redução significativa da germinação, mesmo estando estas armazenadas em condições excelentes $\left(\mathrm{T}=5^{\circ} \mathrm{C}\right.$ e $\left.\mathrm{UR}=40 \%\right)$. Os autores atribuem estes resultados ao alto teor de água presente no material de cobertura.

Desta forma, torna-se necessário que os materiais e aditivos utilizados no revestimento das sementes, bem como, suas dosagens, sejam estudados com relação à sua qualidade, já que alguns destes materiais podem causar efeitos fitotóxicos imediatos na germinação ou reduzir a qualidade fisiológica das sementes durante o armazenamento. Assim sendo, o objetivo deste trabalho foi estudar o efeito de dois tipos de materiais de revestimento sobre a qualidade fisiológica inicial e durante o armazenamento de sementes de tomate e sua associação com fungicidas utilizados no tratamento das sementes.

\section{MATERIAL E MÉTODOS}

O experimento foi conduzido no Laboratório de Análise de Sementes da Universidade Federal de Lavras - UFLA, e na Embrapa Hortaliças, em Brasília - DF.

Foram utilizadas sementes de tomate da cultivar Nemadouro, fornecidas pela Embrapa Hortaliças, onde as mesmas foram revestidas (peletizadas) em uma betoneira adaptada, utilizando dois tipos de materiais: microcelulose + calcário e microcelulose + areia. Como adesivo, foi utilizado a cola Cascorex - PVA (20\%). Uma amostra das sementes recebeu junto com o material de recobrimento o fungicida Rovrin (200g/100kg de sementes), e outra amostra recebeu apenas o material de revestimento. Da mesma forma, uma amostra de sementes nuas foi tratada e outra não tratada com Rovrin. As sementes, após a peletização, foram secadas em estufa de circulação forçada de ar, a $35^{\circ} \mathrm{C}$, por 24 horas, quando atingiram umidade entre 7 e $8 \%$, embaladas em envelopes de papel comum (embalagem permeável) e de papel laminado (embalagem impermeável). Em seguida as sementes foram armazenadas por um período de 24 meses em condições de ambiente no Laboratório de Análise de Sementes da UFLA, onde em média a umidade relativa e a temperatura durante o período foi de $62,8 \%$ e $23,5^{\circ} \mathrm{C}$ respectivamente .

A avaliação da qualidade das sementes foi realizada a cada quatro meses, considerando um envelope de cada embalagem para cada período de avaliação. Para tanto utilizouse as seguintes determinações:

\section{1) Grau de umidade}

Realizado em estufa a $105 \pm 3^{\circ} \mathrm{C}$ por $24 \mathrm{~h}$, conforme metodologia descrita pelas Regras para Análise de Sementes (Brasil 1992).

\section{2) Teste de Germinação e Índice de Velocidade de Ger- minação}

O teste de germinação foi realizado com quatro repetições de 100 sementes por tratamento, semeadas sobre papel mata-borrão em caixa gerbox, conforme recomendações das Regras para Análise de Sementes (Brasil, 1992), obtendo-se 
no final o percentual de plântulas normais. Para o índice de velocidade de germinação, foram realizadas contagens diárias, computando-se o número de sementes germinadas (com protrusão radicular), até atingir a estabilização, quando foi feito seu cálculo conforme a fórmula proposta por Maguire (1962).

\section{3) Teste de Envelhecimento Artificial}

Utilizando-se o método do gerbox adaptado, contendo 40ml de água, 400 sementes de cada tratamento foram espalhadas em camada única sobre uma tela suspensa, dentro de cada caixa gerbox. Posteriormente, essas caixas foram colocadas em câmara de germinação, a $42^{\circ} \mathrm{C}$ por 72 horas. Após este período, as sementes foram colocadas para germinar conforme metodologia descrita para o teste de germinação. As avaliações foram realizadas aos quatorze dias após a semeadura, computando apenas as plântulas normais.

\section{4) Emergência das plântulas}

Foram utilizadas 200 sementes (4x50), semeadas em bandejas plásticas, contendo como substrato uma mistura de solo e areia na proporção de 1:1. Após a semeadura, as bandejas foram mantidas em câmara de crescimento, sob regime alternado de luz e escuro (12h), a $25^{\circ} \mathrm{C}$, por 15 dias. As avaliações foram realizadas diariamente, computando-se o número de plântulas normais emergidas até a estabilização do estande. Foi calculado o tempo necessário para que ocorresse $50 \%$ de plântulas emergidas (T50) e também o estande aos 15 dias.

O delineamento foi inteiramente ao acaso em esquema fatorial 3x2x7 sendo (tipos de revestimento com areia, calcário e não revestidas; sementes tratadas e não tratadas com Rovrin e sete épocas de avaliação 0,4,8,12,16,20 e 24 meses de armazenamento) com análise individual para cada tipo de embalagem. Os dados foram analisados pelo estudo de regressão.

\section{RESULTADOS E DISCUSSÃO}

Pelos resultados da determinação do teor de água das sementes durante o armazenamento, pôde-se verificar que não houve grandes variações, pois mesmo nas sementes que foram armazenadas em embalagem de papel essa variação foi menor do que 1\% (dados não apresentados). Pelos resultados do teste de germinação (Figura 1), nota-se que houve um comportamento semelhante dos diferentes tratamentos para ambas embalagens, durante os 24 meses de armazenamento, sendo que, as sementes não revestidas independente do tratamento fungicida, bem como aquelas revestidas com areia e não tratadas, mantiveram sua germinação ao longo desse período. Já as sementes revestidas com calcário (tratadas ou não) tiveram uma redução na germinação aos oito e 12 meses. Houve ainda uma tendência de aumento aos 16 e 20 meses, e novamente um declínio aos 24 meses, sendo mais acentuado nas sementes tratadas. Isto pode ser atribuído à uma provável restrição da germinação promovida pelo material de revestimento, pois verifica-se visualmente que o pelete formado pelo calcário é mais consistente do que em areia, em função do tamanho dos grânulos, podendo ter dificultado a entrada de oxigênio durante o processo de germinação, e no estágio mais avançado do armazenamento esta impermeabilização tenha sido quebrada. Neste sentido, Sachs et al. (1981), relatam que a maioria dos materiais de revestimento utilizados dificulta a penetração de oxigênio na semente, e a maior resistência está na granulometria do material. Também Tonkin (1979), relata que o material a ser utilizado no revestimento não deve impedir a passagem de oxigênio o que dificulta a germinação.

Pelos resultados do índice de velocidade de germinação (Figura 2), as sementes não revestidas germinaram mais rápido do que as revestidas. Estes resultados estão de acordo com Sampaio \& Sampaio (1994), os quais relatam que sementes revestidas demoram mais tempo para germinar do que as não revestidas em função de uma barreira física promovida pelo material utilizado. Também Folster et al. (1987), verificaram que a velocidade de emergência foi menor em sementes revestidas de cenoura e rabanete. Nota-se ainda, que houve um comportamento semelhante ao de germinação total, com uma pequena redução até aos 12 meses e depois com um pequeno acréscimo no índice. Verifica-se ainda, que as sementes revestidas com calcário, independente do tratamento fungicida, apresentaram índice de velocidade menor do que as sementes revestidas com areia, reafirmando mais uma vez o efeito impermeabilizante do calcário nas sementes. Com relação à embalagem, as sementes tiveram um comportamento semelhante (Figura 2).

Pelos resultados do teste de envelhecimento acelerado, apresentados na Figura 3, observa-se também um comportamento semelhante aos demais testes, ou seja, o vigor das sementes não revestidas manteve-se praticamente inalterado ao longo do armazenamento. As sementes revestidas com areia tiveram uma pequena redução do vigor, sendo que aos 24 meses o vigor dessas sementes foi praticamente idêntico às não revestidas. Já as sementes revestidas com calcário apre- 
Embalagem permeável

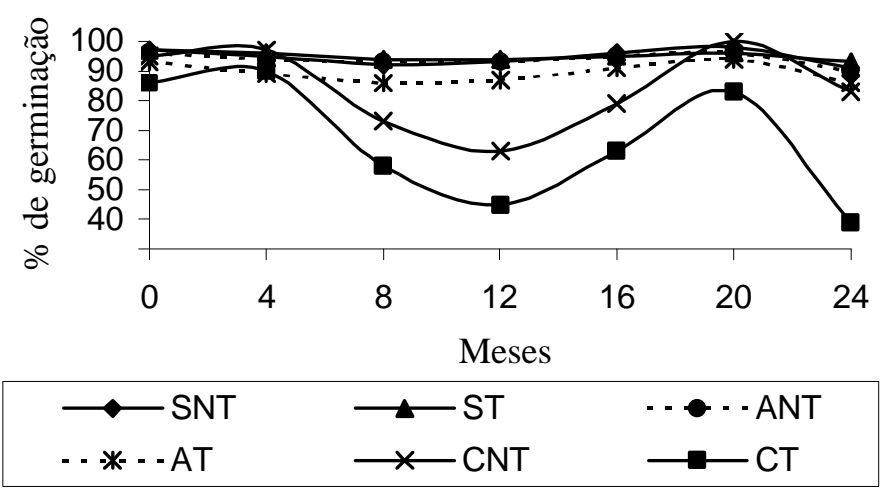

Embalagem impermeável

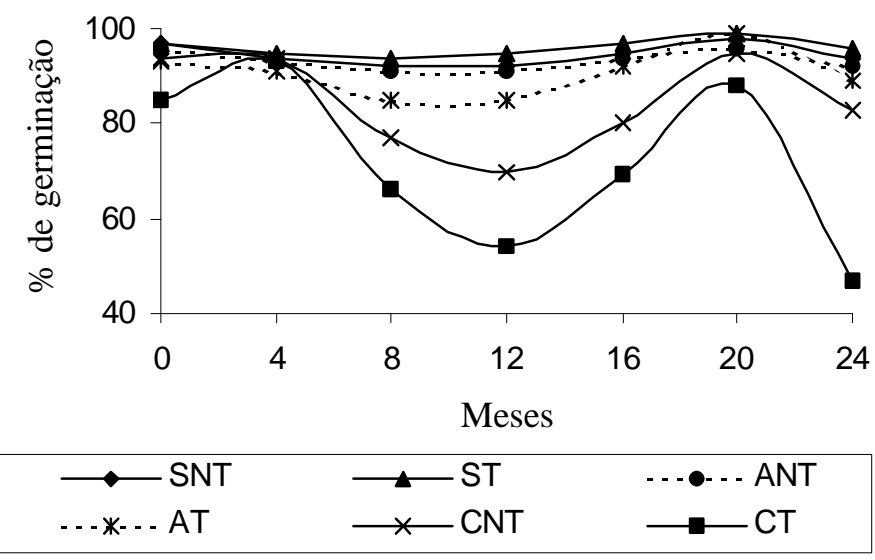

FIG. 1. Resultados médios de germinação de sementes de tomate revestidas com dois materiais, armazenadas em embalagem permeável e impermeável, durante 24 meses. SNT-Sementes nuas não tratadas; ST-Sementes nuas tratadas; ANT Sementes peletizadas com areia e não tratadas; AT-Sementes peletizadas com areia e tratadas; CNT-Sementes peletizadas com calcário e não tratadas; CT-Sementes peletizadas com calcário e tratadas. UFLA, Lavras-MG. 2002.

\section{Embalagem permeável}

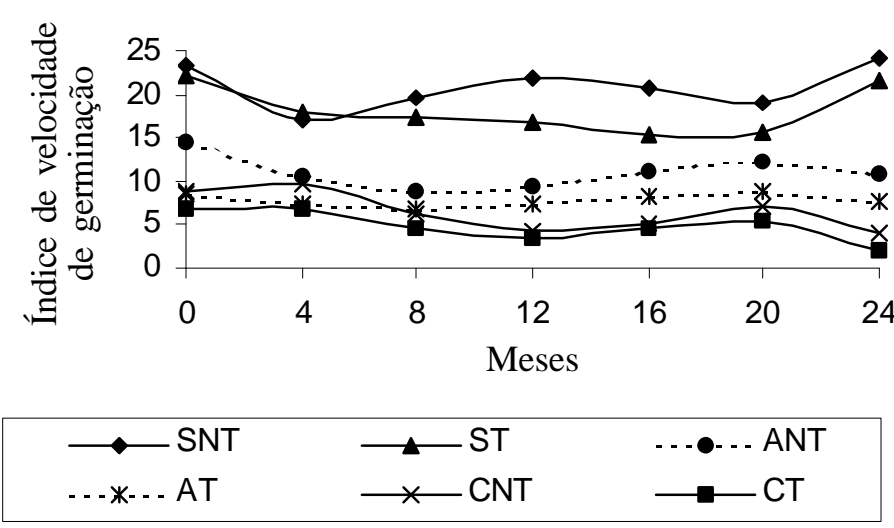

Embalagem impermeável

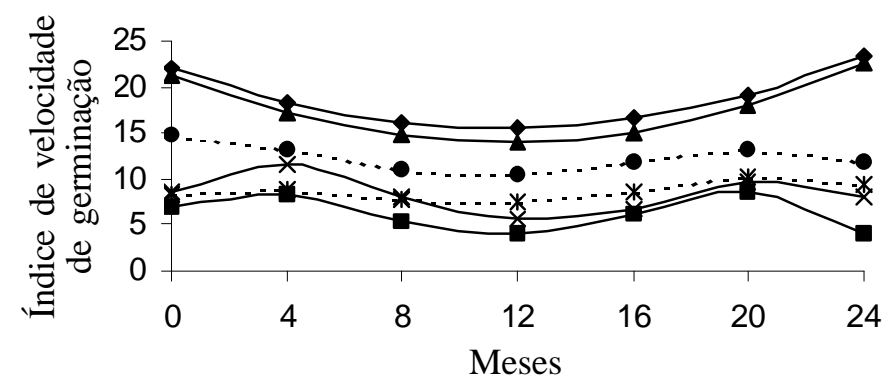

\begin{tabular}{lll|}
$\longrightarrow \bullet$ SNT & $\longleftarrow$ ST & $\ldots \bullet$ ANT \\
$\ldots$... AT & $\longrightarrow$ CNT & $\longrightarrow$ CT \\
\hline
\end{tabular}

FIG. 2. Resultados médios do índice de velocidade de germinação de sementes de tomate revestidas com dois materiais, armazenadas em embalagem permeável e impermeável, durante 24 meses. SNT-Sementes nuas não tratadas; ST-Sementes nuas tratadas; ANT-Sementes peletizadas com areia e não tratadas; AT-Sementes peletizadas com areia e tratadas; CNT-Sementes peletizadas com calcário e não tratadas; CT-Sementes peletizadas com calcário e tratadas. UFLA, Lavras-MG. 2002.

sentaram menos vigorosas mesmo no início do armazenamento, com redução acentuada durante o armazenamento, principalmente naquelas que foram tratadas, revelando que o fungicida em associação com o material de revestimento favorece uma deterioração mais rápida.

Nos resultados do teste de emergência em bandeja, notase que as sementes não revestidas apresentaram emergência
(T50) mais rápida do que as sementes revestidas (Figura 4). Estes resultados estão de acordo com aqueles obtidos por Kitto \& Janick (1985), os quais trabalhando com sementes revestidas de alface, chicória, tomate e cebola, verificaram um atraso de um a dois dias no período da emergência das plântulas, sem contudo, afetar o estande final. Observa-se também que não houve grandes alterações na velocidade de ger- 
Embalagem permeável

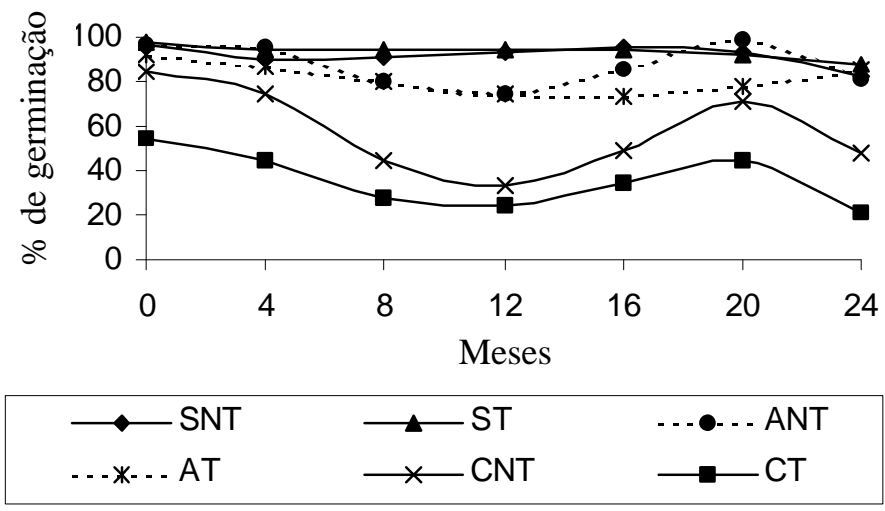

Embalagem impermeável

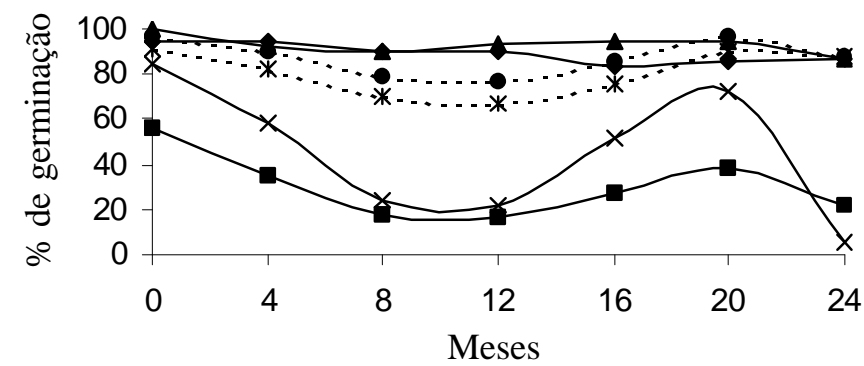

$\begin{array}{lll}\longrightarrow \text { SNT } & \longleftarrow \text { ST } & \ldots \bullet \text { ANT } \\ \ldots * \ldots \text { AT } & \longleftarrow \text { CNT } & \longrightarrow\end{array}$

FIG. 3. Resultados médios de germinação após o teste de envelhecimento acelerado de sementes de tomate revestidas com dois materiais, armazenadas em embalagem permeável e impermeável, durante 24 meses. SNT-Sementes nuas não tratadas; ST-Sementes nuas tratadas; ANT Sementes peletizadas com areia e não tratadas; AT-Sementes peletizadas com areia e tratadas; CNT-Sementes peletizadas com calcário e não tratadas; CT-Sementes peletizadas com calcário e tratadas UFLA, Lavras-MG. 2002.

\section{Embalagem permeável}

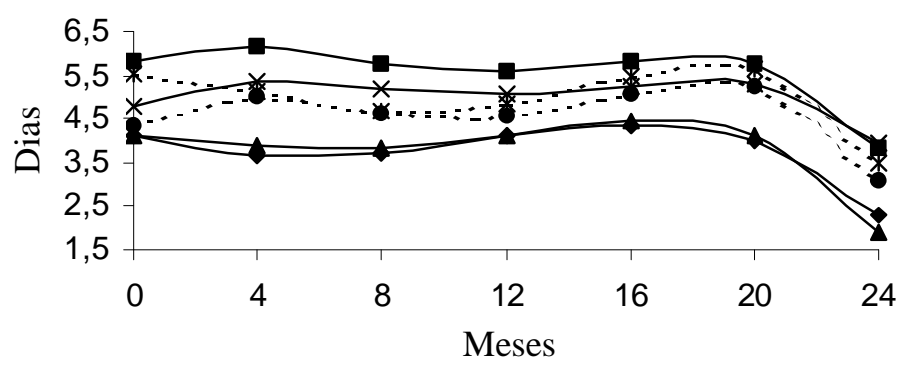

Embalagem impermeável

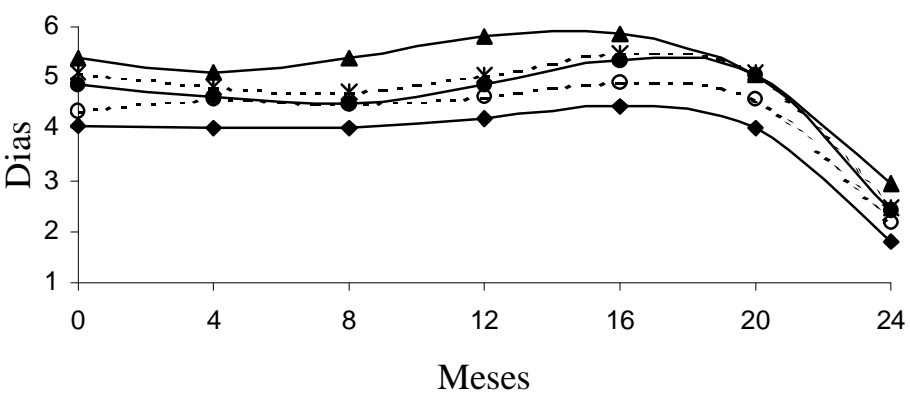

FIG. 4. Resultados médios em dias para que ocorrasse $50 \%$ de germinação (T50) de sementes de tomate revestidas com dois materiais, armazenadas em embalagem permeável, e impermeável, durante 24 meses. SNT-Sementes nuas não tratadas; ST-Sementes nuas tratadas; ANT- Sementes peletizadas com areia e não tratadas; AT-Sementes peletizadas com areia e tratadas; CNT-Sementes peletizadas com calcário e não tratadas; CT-Sementes peletizadas com calcário e tratadas; S-Sementes nuas; A-Sementes peletizadas com areia; C-Sementes peletizadas com calcário e; NT-Sementes não tratadas; T-Sementes tratadas UFLA, Lavras-MG. 2002.

minação durante o período em que as sementes ficaram armazenadas, e somente aos 24 meses é que esta redução foi mais acentuada. Nota-se ainda que as sementes revestidas com areia tiveram um comportamento semelhante às não revestidas, conforme verificado pelo índice de velocidade de germinação (Figura 2).
Na Figura 5, pelos resultados de percentagem de plântulas normais emergidas no teste em bandeja, observa-se que para as sementes não revestidas e armazenadas em embalagem permeável, houve uma pequena redução na qualidade apenas no final do armazenamento. Entretanto, aquelas sementes que foram revestidas e armazenadas nesse tipo de embalagem, 
Embalagem permeável

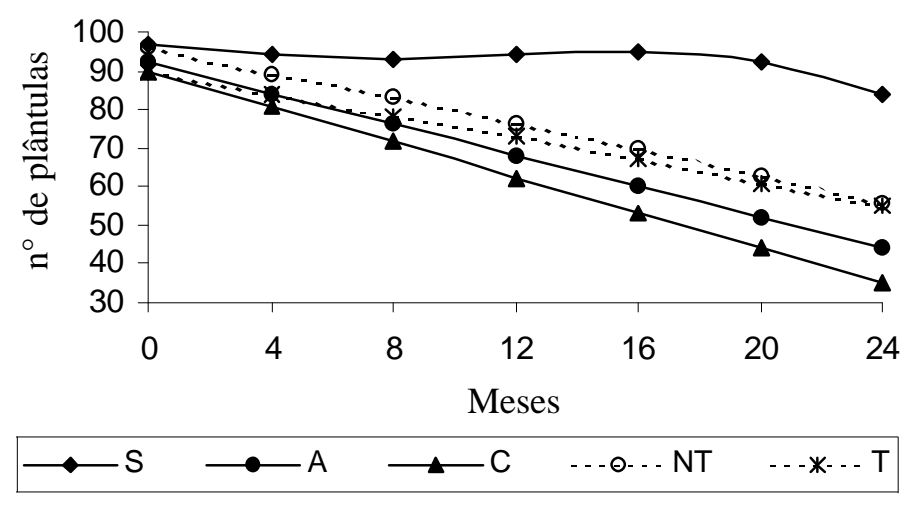

Embalagem impermeável

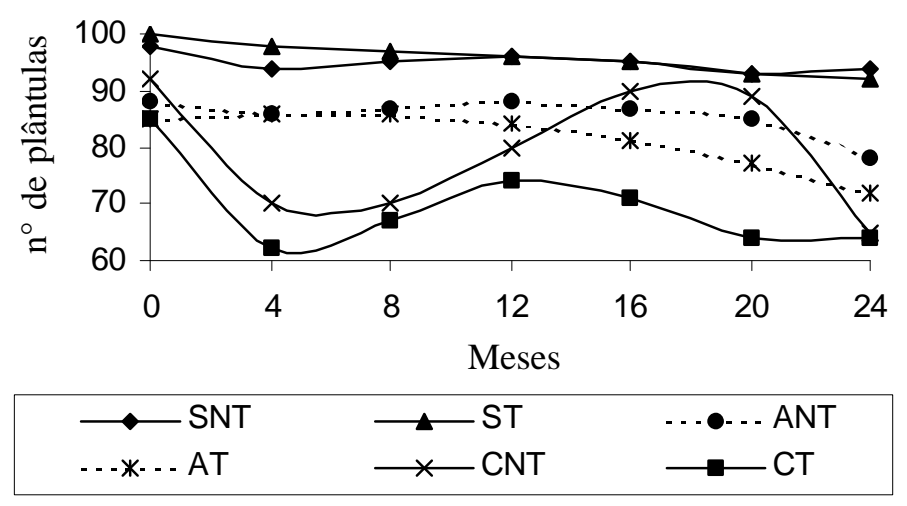

FIG. 5. Resultados médios de plântulas emergidas de sementes de tomate revestidas com dois materiais, armazenadas em embalagem permeável e impermeável, durante 24 meses. SNT-Sementes nuas não tratadas; ST-Sementes nuas tratadas; ANT- Sementes peletizadas com areia e não tratadas; AT-Sementes peletizadas com areia e tratadas; CNTSementes peletizadas com calcário e não tratadas; CT-Sementes peletizadas com calcário e tratadas; S-Sementes nuas; A-Sementes peletizadas com areia; C-Sementes peletizadas com calcário e; NT-Sementes não tratadas; T-Sementes tratadas UFLA, Lavras-MG. 2002.

independente do material de revestimento utilizado a redução do estande foi bastante significativa e linear. Para as sementes armazenadas em embalagem impermeável, a redução no estande foi menor, independente do tipo de tratamento recebido. Verifica-se também que as sementes revestidas com calcário + microcelulose apresentaram uma redução no estande a partir do início do armazenamento e a seguir um acréscimo, conforme foi verificado nos demais testes, confirmando mais uma vez que existe uma barreira impedindo a germinação. Observa-se ainda, que a partir de 16 meses de armazenamento as sementes que foram revestidas com esse material tiveram seu estande reduzido, e provavelmente deve ter havido um efeito deteriorativo das sementes em função do material de revestimento, pois de acordo com Roos \& Moore (1975) dependendo do tipo de material utilizado no revestimento das sementes, pode-se acelerar o processo de deterioração.

\section{CONCLUSÕES}

- Sementes revestidas com calcário deterioram mais rapidamente do que com areia;

- sementes tratadas com fungicida em associação com os materiais de revestimento perdem sua qualidade mais rápida no armazenamento;
- sementes de tomate não revestidas e revestidas com areia + microcelulose e sem tratamento fungicida mantiveram sua qualidade durante 20 meses de armazenamento, independente da embalagem utilizada;

- sementes revestidas apresentam uma germinação mais lenta do que as não revestidas.

\section{REFERÊNCIAS}

ANTONOV, I.; SLAVOV,K.; PURVANOV,P.; STANCHEV. S. Pelleting of sugar beet seed and of some other crops. Plant Science, Strasbourg, v.15, p.32-36, 1978.

BORDERON, M.A. Semences de cereales: le pelliculage cagne du terrain. Cultivar, Pelotas, V.253, p.34-35, 1989.

BRASIL, Minsitério da Agricultura e Reforma Agrária. Regras para Análise de Sementes, Brasília, 1992, 365p.

CORASPE, H.M. Avaliação do efeito da peletização sobre o vigor de sementes de alface (Lactuca sativa L.). Scientia Agrícola, Piracicaba, v.50, n.3, p.349-354, 1993.

FOLSTER, E.; POTZ, H.; SCHILDMEYER, A. Do pelleted seeds germinate later? Horticultural Abstract, Hannover, v.57, n.11, p.895, 1987.

HENRIKSEN, K. Seed type and sowing techniques for onion. Horticultural Abstract, Arlesv, v.57, n.4, p.263 1987.

JEONG, Y.O.; CHO, J.L. Effect of coating materials and priming on seed germination of tomato and pepper. Journal of the Korean for Horticultural Science, Korean, v.36, n.2, p.185-191, 1995. 
KITTO, S.L.; JANICK, J. Production of synthetic seeds by encapsulating asexual embryos of carrot. Journal American Society Horticultural Science, Alexandria, v.110, n.2, p.277-282, 1985.

LASKA, P.; BARTOS, J.; ROD, J. Pelleting of cabagge seed using carbofuran, benomyl and thiram with sacrust against pests and diseases. Horticultural Abstract, Olomouc, v.56, n.9, p.739, 1986.

MAGUIRE, J.D. Spped og germination aid in selection and evaluation for seedling and vigour. Crop Science, Madison, v.2,n.2, p.176-177, Mar./Apr. 1962

MARIONI, L. The development of planting techniques for tomatoes and Capsicums in the Tuscan Maremma. Notiziario di Ortoflorofruticoltura, Bologna v.8, p.123-130, 1982.

RODRIGUEZ DEL RINCO, A. Condiciones para la Siembra Directa del Pimiento. Mesa Redonda: Siembra Directa de Pimiento. INIA, Madrid, p.13-16, 1988.
ROOS,E. E.; MOORE, F.D. Effect of seed coating performance of lettuce seeds in greenhouse soil tests. Journal American Society Horticultural Science, Alexandria, v.100, p.573-576, 1975.

ROSSO, F.; MERIGGI,P.; MAINES, G.; PAGANINI,U. Surgarbeet: Seed pelleting and defence, innovative technical aspects. Infomatore Agrario, Verona, v.51, n.27, p.58-64, 1995.

SACHS, M.; CANTLIFFE, D.J.; NELL, T.A. Germination studies of clay-coated sweet pepper seeds. Journal American Society Horticultural Science, Alexandria, v.106, p.385-389, 1981.

SAMPAIO, T.G.; SAMPAIO, N.V. Recobrimento de sementes. Informativo ABRATES, Brasília, v.4, n.3, p.20-52 dez. 1994.

SCOTT, J.M. Seed coatings and treatments and their effects on plant establishment. Advances in Agronomy, San Diego, San Diego, v.42, p.43-83, 1989.

TONKIN, J.H.B. Pelleting and other presowing treatments. Advances of Seed Technology, New York, v.4, p.84-105, 1979. 